\title{
Research on Path of Improvement for Chinese Administration Service Efficiency from the Perspective of Standardization
}

\author{
Hui Liu \\ China National Institute of Standardization \\ Beijing, China \\ Liuhui2604@163.com
}

\begin{abstract}
The research purpose of the paper is to discuss the significance and function mechanism of standardization in improvement of administration services efficiency and make suggestions to promote standardization of administration services. Firstly, the connotation and features of administration services are clarified and the current situation and development trend of Chinese administration services are explored. And then it focuses on analyzing the mechanism of standardization in improvement of administration services efficiency and elaborates current situation and local practice of administration services standardization in China. The research results indicate that standardization has an obvious role in improvement of administration services efficiency. The innovation of the paper lies in researching the improvement of administration services efficiency from the perspective of standardization and proposing a new perspective for research into administration services.
\end{abstract}

Keywords-standardization of administration services; efficiency; function mechanism; practice

\section{INTRODUCTION}

At present, the Chinese government has made great effort to promote reform of "streamline administration and institute decentralization, combination of delegation and administration, service optimization", and optimizing business environment, with a view to stimulating and releasing market vitality. In recent years, the research of the academic world on administration services has gradually become the hotspot. However, literature review indicates that there are fewer research achievements on standardization of administration services at home and abroad at present and more researches focus on Administration services and Internet Plus administration services Initiative and other fields. Andersen and Jakobsen have discussed the impact of integration pressure of institutionalization model, performance information and political pressure of other organizations and other external factors on government innovation [1]. Amit Das, Harminder Singh, Damien Joseph have researched the impact of change of affluence degree, information and communication technology (ICT) infrastructure, human capital and governance level on maturity of global e-government administration [2]. Taking 13 governmental agencies of India as an example, Shivraj Kanungo and Vikas Jain have analyzed the impact of organizational culture on the success of e-government administration plan [3]. Taking 31 provincial administrative regions of China (excluding Hong Kong, Macao and Taiwan in China) as research objects, Han Nana has explained the generative logic of the online administration services capacity of Chinese provincial governments with qualitative comparison and analysis methods of fuzzy sets [4]. Wang Fashuo has selected six explanatory variables at three levels, respectively government resources and support, social demand and local economic development, to analyze influence factors of "Internet + Administration Services" capacity of Chinese provincial governments [5]. Tang Zhiwei, Guo Yuhui and Zhai Yuanfu hold that the development of online handling capacity of administration services mainly depends on the joint influence of social system, technical system and external environment [6].

\section{CONNOTATION AND FEATURES OF AdMINISTRATION} SERVICES

\section{A. Connotation of Administration Services}

As the core of government services, administration services are both the basic function of the government and the starting point for operation of public power as well as regression of government mission and value [7]. As for the definition of administration services, there is no unified understanding at home and abroad at present. From the perspective of behavior, administration services are actions that all levels of governments and departments handle administrative licensing, non-administrative licensing approval, public services and other administration matters for citizens, legal persons and other organizations by law [8]. From the perspective of process, administration services are processes that administration services functions are continuously strengthened and public interests are realized through reasonable and normative coordination and operation with efficient and highquality public products and public services as an objective under the guidance of citizen-based concept [9]. Generally, administration services are actions that administrative bodies and enterprises, as well as public institutions, directly provide the public with specific matter-handling service matters as per legal functions. 
the administration services. Different from general services, the administration services must make prompt and responsible responses to the demands of citizens and organizations.

\section{4) Embodiment of openness and transparency.}

As the government is one party to the social deed, it means that the exercising of public rights must be open and transparent instead of being confident like commercial services. The right to know is owned by citizens and openness is also the obligation of the government. Openness and transparency may guarantee that citizens have the right to know. requirements and customer first". On the whole, administration services have the following features.

1) Insistence on demand orientation, service orientation and citizen orientation

Like other services, administration services highlight demand orientation and embody the value of service itself. In the field of public management, services are reflected in that the service subjects provide all altruistic work or activities for the service objects to satisfy social demand, with a view to realizing effective social management and public goods supply. In particular, public order maintenance, public environment protection and maintenance of other public benefits involving national interest and people's livelihood are main fields for administration services. Hence, administration services must be demand-driven. The administration services highlight service orientation and citizen orientation and the essential difference between administration services and commercial services are mainly reflected in that the objects of administration services are not simply “customers”, but clients, citizens with rights (legal persons).

\section{2) Balancing fairness and efficiency}

The natural defect of monopoly is low efficiency which is also prone to cause power rent-seeking. New public administration school represented by H. George Frederickson explicitly proposes that although economy and efficiency are one of values and objectives to be pursued by public administration, the core value is advocating of social equity value and the core value of public administration lies in social fairness and promoting the basic value owned by the civil society centering upon social equity [10]. As public services, the administration services belong to public resources and equality is the basic attribute of public services. The subjects of administration services are governments and powers of governments originate from alienation of people's rights. Governments are results of people's entering into contracts and transferring powers. As public resources, equality of the administration services has become the basic value of services.

3) Multiple subjects are involved and their requests are reflected

The governance theory is widely applied in governments of all countries in the world and it highlights participation of social organizations, citizens and multiple subjects in public administration. It requires coordination, dialogue and negotiation between elements of social system to pursue wide consensus and participation. The administration services are oriented at many stakeholders. During the service process, citizens are not only receivers of administration services, but also partners, participants, supervisors and even designers of

\section{CURRENT SITUATION AND DEVELOPMENT TREND OF CHINESE ADMINISTRATION SERVICES}

Firstly, transition from decentralized approval to centralized acceptance. In the 1980s, China entered the stage of comprehensive reform and opening-up. To better advance investment promotion, support development of local economy, the pioneering undertaking for taking centralized administration services as local practice formally stepped onto the historical stage and gradually extended to other social fields from serving foreign-funded enterprises. In particular, after formal issuance and implementation of Administrative Licensing Law in 2003, the innovation of administration services mode represented by administration services center began to spring up and extended to small, medium and large cities, counties, streets and towns throughout the country. As of April, 2017, the people's governments above county levels nationwide had established 3,058 government affair halls, with coverage rate of $94.3 \%$. In particular, departments of the State Council established 42 government affairs halls. There were 19 provincial government affairs halls (including Xinjiang Production and Construction Corps), 323 prefecture-level city government affair halls, 2623 county-level government affairs halls and 93 directly-controlled municipality and county-level government affair halls. In addition, 38513 service centers for the convenience of people had been established in the villages and towns (streets), with coverage up to 96.8\%; whole coverage of provincial, municipal and county-level government affair halls had been basically realized in 7 provinces (districts), i.e., Jiangxi, Guangxi, Sichuan, Guizhou, Yunnan, Gansu and Ningxia.

Secondly, transition from centralized acceptance to intensive handling. In 2008, Wuhou District, Chengdu took the initiative to set up Administrative Review and Approval Bureau in the country. At the end of 2016, pilots with Administrative Review and Approval Bureau independently set up had been distributed in 16 provinces and 160 cities (including 4 provincial cities, i.e., Yinchuan, Xining, Nanning and Shenyang), counties and districts. The Administrative Review and Approval Bureau has overcome plights encountered by government administration mode. Through "separation of review and management, power centralization", the review \& approval and regulation functions are mutually isolated and the review \& approval functions distributed in all functional departments are separated for transfer, integration and centralization again. In addition, a new department, Administrative Review and Approval Bureau is established to exercise rights uniformly. The establishment of Administrative Review and Approval Bureau further boost the transformation 
processing for specific declaration documents required by matter handling, matter handling process, job duties, matterhandling time limit and basis to realize such objective. Boosting the standardization of administration services is the inherent requirement of repeated characteristics of administration services actions, effective tool to maintain excellent management level and service quality, valid means to normalize administration services and basic precondition to realize seamless linking of review and approval step. The core of standardization of administration services is to normalize the discretion of administrative review and approval, namely to subdivide and clarify fuzzy elements in administration actions and better build a government satisfying the people. Specifically, the standardization of administration services should realize the following objectives:

\section{1) Normalizing service actions}

Standardization is intended to limit the discretion in the service process, eliminate randomness and difference of behaviors in administration services process and improve normalization and stabilization of services.

\section{2) Controlling quality of administration services}

Standardization is a spiral rising process of "formulation, execution, evaluation, improvement, re-execution”. On one hand, standardization of administration services is to simplify, combine and reduce intermediate links of handling process of service matters and realize optimization of service quality of single matter; on the other hand, through service standardization, it can integrate powers of related departments and realize seamless lining centering upon the project. In this sense, standardization is both a tool to normalize behaviors of service personnel, and also a stabilizer to guarantee "convenient, transparent, smooth and efficient" administration services quality.

\section{PRACTICE OF STANDARDIZATION OF CHINESE ADMINISTRATION SERVICES}

The standardization of administration services originates from standardized quality management system of the enterprise. The standardization means establishment of terms for joint use and repeated use with regard to realistic problems or potential problems and preparation, release and application of documents in order to obtain the optimal order and promote common benefit within the given scope. Standardization of administration services is a purposeful scientific activity that standards are formulated and implemented with regard to joint and repeated administration services and work arising during administration services and implementation of standards is supervised and continuously improved. Through formulation and implementation of administration service standards and application of standardized principles and methods, it can realize the purpose of clarification of service scope, the objective orientation of service quality, normalization of service method and routinization of service process, thus obtaining high-quality services.

\section{B. Function Mechanism of Standardization in Improvement of Administration Services Efficiency}

The standardization of administration services is mainly normative, institutionalized and unified integration and

\section{A. Current situation of Standardization of Chinese Administration Services}

At present, in the standardization field of Chinese administration services, Working Group for Standardization of National Administrative Review and Approval and Working Group for Standardization of National Government Affair Hall Service have been established. As for the Working Group for Standardization of National Administrative Review and Approval (SWG14), Approval System Reform Office of the State Council is responsible for preparation and business guidance and the scope of the working group covers common base of administrative review and approval, conditional construction, information-based construction, service specification, supervision evaluation, etc. One national standard GB/T 37277-2018 Work Guideline on Facilitation of are being studied, including Method and Technical Code for Optimization of Administrative Licensing Process (20190795T-469), Classification and Coding of Administrative Licensing Matters (20180980-T-469), Code on Administrative Licensing Approval and Decision (20173542-T-469), Guideline on Evaluation of Satisfaction of Administrative Licensing Approval Services has been issued and six national standards 
Services (20173808-T-469), Code on Application and Acceptance of Administrative Licensing (20173988-T-469), Guideline on Evaluation of Normalization of Administrative Licensing (20173989-T-469); as for the Working Group for Standardization of National Government Affair Hall Service (SWG15), Shandong Quality and Technology Supervision Bureau makes preparation for its establishment and the standardization administration takes charge of guidance. The scope of the working group covers basic terminology of government affair hall service, standardization work guideline, service classification, information services of government affair hall, public resource transaction services, benefit guarantee services, organization management and operation of government affair hall, construction of service platform, performance assessment, etc. 3 national standards GB/T 36112-2018 Code on Site Service Management of Administration services Center, GB/T 36113-2018 Code on Service Complaint Handling of Administration services Center, GB/T 36114-2018 Code on Preparation of Service Guidelines of Matters of Administration Services Center have been prepared and 4 national standards are being studied, including Classification and Coding Rules of Administration Services Matters (20190793-T-469), Code on Evaluation of Service Satisfaction of Administration Services Center (20190794-T469), Code on Credit Rating and Evaluation of Preintermediate Agency of Administration Services (20190792-T469), Service Code on Agency for Handling Approval of Construction of Investment Project (20173807-T-469).

\section{B. Issuance of National Standard Work Guideline on Facilitation of Approval Services}

In recent years, to improve review and approval service efficiency and enhance the sense of gain of the people, local governments of all levels have made many useful attempt and exploration and a lot of typical practices have sprung up, such as reform of "coming once at most" of Zhejiang Province, "review and approval without handling face to face" in Jiangsu Province, new "one-door and one-network" administration services mode of Foshan, Guangdong Province", reform of "immediate handling, online handling and one-time handling" of Wuhan, "one seal for review and approval" of Binhai New District, Tianjin. On the basis of reform of "four lists and one network", Zhejiang Province has implemented the reform of "coming once at most". At the end of 2017, the matters of "coming once at most" of Zhejiang Province had covered $80 \%$ cases handled, basically realizing "the principle of coming once at most with the exception of coming for many times" and making the people acquire real sense of gain, happiness and safety. As for Foshan, Guangdong Province, supported by "Internet +" technology, new "one-door and one-network" administration services mode for handling matters at one door and enjoying whole-course services with one network has been realized. Jiangsu Province insists on problem orientation and comprehensively boosts reform of "review and approval without handling face to face" to form the matter handling mode of "online handling, centralized approval, joint review, regional evaluation, agency without handling face to face”. In Shanghai, more efforts have been made to reform business environment and formulated and introduced the action plan and ten special action plans. In Wuhan, Hubei Province, with the concept of integration, intelligence and sharing, the reform of "immediate handling, online handling and one-time handling" for review and approval services have been deeply implemented. As for Binhai New District, Tianjin, centering upon "facilitation of review and approval services and normalization of power operation", "one seal for review and approval" has been realized.

On December 28, 2018, the Standardization Administration of the People's Republic of China (SAC) issued GB/T372772018 Work Guideline on Facilitation of Approval Services with the 2018 No. 17 announcement and it was formally implemented since April 1, 2019. The standard has specified matter scope of facilitation of approval services, basic work, informing services, online services, on-site services, inspection and evaluation and other contents. On one hand, issuance of the standard has consolidated and deepened reform achievements of administration services. At the current development stage of the facilitation work of approval services, the standardized methods are used to systematically and collaboratively normalize approval services; breakthrough isolated Information Island, and strengthens supervision and random inspection. On the other hand, it has optimized and improved approval service efficiency. The standard has clarified requirements for matter rearrangement, process optimization, window set up, system constructions, and normalized main contents including on-site services, online services to practically solve difficult, painful and blocking points encountered by the people and governments when handling matters in the government, with significance to deeply boost national supply-side structural reform and optimize business environment..

\section{CONCLUSION}

At present, the standardization of Chinese administration services has just started and it is suggested to carry out work in the following aspects.

Firstly, the standardization of administration services should focus on the main and difficult points of government management and services and be aligned with the strategic deployment of government reform. It is required to carry out overall planning and design from the perspective of comprehensively improving government governance system and modernize governance capacity, build the boosting system for standardization of administration services from the central government to local places, clarify functions and responsibilities of all parts, and determines specific tasks, implementation plans and schedules.

Secondly, it is important to fully exert the dominant role of the government, strengthen construction for standardization of administration services, clarify and normalize administration services standard, establish a comprehensive, scientific and effective administration services standard system. It is required to accelerate formulation of related standards and consider differences between all places in combination with basic national conditions of China. At the same time, it is needed to boost application of cloud computing, big data, IoT, mobile Internet and others and continuously improve facilitation, individualization, and intelligence and securitization level of online administration services. 
[2] Amit Das, Harminder Singh, Damien Joseph. A longitudinal study of egovernment maturity. Information and Management, 2017, 54(4), pp.415-426.

Thirdly, it is needed to fully exert the role of the government in the implementation of standards, normalize management of standardization means and improve public service efficiency. In addition, it is necessary to exert the role of pilot demonstration project in boosting implementation of standards, boost standard publicity and promotion driven by pilot demonstration project, strengthen information feedback of implementation of standards, verify implementation effect of standards, summarize and obtain successful experience boosting implementation and application of standards on the basis of pilot demonstration, organize promotion application in the industry or field, and comprehensively advance implementation and application of standards in the field of social management and public services.

Fourthly, it is suggested to take various forms and means to cultivate a batch of professional talents mastering standardization knowledge and familiarizing themselves with administration services as soon as possible. It is needed to strengthen top-level design and planning of talent cultivation and growth, build the talent cultivation and development plans, plan the standardized talent cultivation and boost the standardized professional education.

\section{REFERENCES}

[1] Simon Calmar Andersen, Mads Leth Jakobsen. Political Pressure, Conformity Pressure, and Performance Information as Drivers of Public Sector Innovation Adoption. International Public Management Journal, 2018, 21(2), pp.213-242.

[3] Shivraj Kanungo, Vikas Jain. Organizational Culture and E-Government Performance: An Empirical Study. International Journal of Electronic Government Research, 2011, 7(2), pp.36-58.

[4] Han Nana. Generation logic and mode of online government service ability of provincial government in China: Qualitative comparative analysis of fuzzy sets based on 31 province data, Journal of Public Administration,2009,(4), pp.82-100.

[5] Wang Fashuo. Influence factors of provincial government's "Internet + government services" capability: Qualitative comparative analysis based on 30 provincial government samples, Journal of Northeastern University (Social Science), 2019, (2), pp.173-179.(In Chinese)

[6] Tang Zhiwei, Guo Yuhui, Zhai Yuanpu. Research on online management ability of government service under the framework of society and technology: Data analysis based on 334 prefecture-level administrative regions, Chinese Public Administration, 2019, (1), pp. 3744. (In Chinese)

[7] Ai Lin, Wang Gang. Remolding government service for the public, Beijing: Social Science Literature Press, 2015. (In Chinese)

[8] Kong Fanbin, Zheng Jiahao, Liu Minghou. Making full use of the construction of government service center and deepening the reform of administrative management system [A]. Jiangsu Institute of administration. An empirical study on government management, 2010. Research Report of Jiangsu Administrative Management Society[C]. Nanjing: Jiangsu People's Press, 2013. (In Chinese)

[9] Pi Zongping, Sun Guojun, Yin Zheng. Research on Jiangsu government affairs publicity and government affairs service evaluation system [A]. Jiangsu Institute of administration. Research on government management innovation, 2014. Research Report of Jiangsu Administrative Management Society[C]. Nanjing: Jiangsu People's Press, 2015. (In Chinese)

[10] H.George Frederickson. New Public Administration. Beijing: China Renmin University Press,2011. 